\title{
THE ROLE OF EU INNOVATION POLICIES IN THE SUSTAINABLE DEVELOPMENT OF THE ENERGY SECTOR
}

\author{
Olesea SIRBU \\ Academy of Economic Studies of Moldova, Republic of Moldova \\ Rodica CRUDU \\ Academy of Economic Studies of Moldova, Republic of Moldova \\ Augustin IGNATOV* \\ Academy of Economic Studies of Moldova, Republic of Moldova
}

\begin{abstract}
In the present conditions when the demographic pressure upon the environment is higher than ever, the humanity faces the challenge of sustainability. Namely the sustainability of human activities is important and nothing can assure it better than sustainable energy supplies. The European Union is the leading global power in terms of adjusting its policies to increase innovation to assure a sustainable growth of its energy sector as a key to an advanced economic system. The present research focuses on the impact of European Union policies on the sustainable development of its energy sector by analyzing quantitatively and qualitatively various indicators intended to offer a throughout insight. The results obtained focus on the identification of the main innovation paradigms; the description of the main modern environmental challenges, especially in the energy domain; the determination of the relation between innovation and energy sustainability, and its analysis at the level of European Union.
\end{abstract}

JEL classification: H50, Q20, Q40, Q50;

Keywords: sustainable economic development; renewable energy; greenhouse gas emissions; recycling; energy efficiency; R\&D expenditure

\footnotetext{
* Corresponding author. Address: Centre for Studies in European Integration, Academy of Economic Studies of Moldova, Banulescu-Bodoni 61 street, MD-2005, Chișinău, Republic of Moldova, E-mail: augustin1ignatov1@gmail.com
} 


\section{Introduction}

One of the biggest challenges the humanity has ever faced is: to meet the growing needs of world's population without increasing the anthropic pressure upon the environment. Thus, billions of dollars are yearly allocated to re-think the present global economic system. A special attention is given to the modernization of the energy sector, cleaner and more sustainable energy being the key for a more secure future. The European Union is ahead of all global powers in terms of re-structuring its economic potential through innovation driven processes to meet the sustainability goals. Taking into account these conditions, the main aim of the present paper is: to identify the relation between the EU's expenditures on innovation and the development of its energy sector, which is the main driver of socio-economic sustainability. The objectives to be achieved by the research include the analysis of the main paradigms driving innovation; the most important challenges of EU's energy sector; the initiatives to tackle them; the identification of the relation between innovation and sustainable development and the provision of relevant conclusions.

Despite the multitude of materials available on this subject, the present paper comes to evaluate the efficiency of European R\&D expenditure by assessing its effects upon innovation and energy sustainability.

\section{Literature review}

To most effectively explore the issues related to the EU innovation policies and the sustainability of its energy sector a subset of literature has been selected to identify the best which is the motivation to innovate and what are the socioeconomic benefits of innovation. Moreover, it is proposed to point out which are the existing impediments hampering the progress of the EU's energy market.

Thus, as far back as 2001, Williams stated that the industrialized countries, including most of the EU states, need radical changes in their energy systems in order to address effectively the multiple economic, social, environmental, and insecurity challenges posed by conventional energy. In such a way, fundamental policy changes are required to increase the attention given to the energy sector's sustainability since it is the core to progressive economic development. Costantini and Crespi (2009) underline that innovation in the energy sector for most of industrialized countries, especially for the European Union ones, is crucial because energy technologies allow enhancing the countries' competitive economic advantages improving their capacities to face higher economic competition without increasing the pressure upon the environment and climate. Ragwitz et al (2009) says that policies promoting technological innovation in the energy area lead to a continuous and sufficiently fast reduction of the energy technologies' development costs. However, the implementation of these policies is only relevant when having a proper international cooperation framework intended to create larger markets providing increased possibilities to exploit economies of scale and accelerate research and development in this area. In such a way, it is necessary to remark that in order to make the energy sustainable through innovation the proper innovation should be sustainable. It is essential to produce a more systematic and detailed account of the complete range of measures and means used to support policies (at national and local levels) aimed at promoting green innovations and in fact create a market with growing demand for innovation (Hamdouch and Depret, 2012). 
The European House "Ambrosetti" (2015) in its research for Enel, stated that the key to energy sustainability in the European Union is a well-balanced energy market regulation. It makes sure that investments are based on long-term market considerations and price signals. Being one of the largest energy companies of Europe, Enel pays increased attention to new technologies as they contribute to increase the energy security by reducing import dependency and exposure to the volatility of fossil fuel prices and it also brings significant air pollution and health cobenefits. Yet, it is mentioned that the energy innovation investments in the EU will not reach the full potential unless the disparities among countries are eradicated and is not completed the formation of the unique energy market (Prandecki, 2014). The consolidation of the EU energy market including the development of common innovative infrastructure projects would enhance the competition in the field encouraging the growth of competitiveness which will result in lower price and higher quality (Costa-Campi et al, 2013). Moreover, the consolidation should take into account the flexibility dimension which is important to create favorable preconditions to enhance its sustainability. In such a way, the European Union policies should focus on the demand side rather than supply to fully embrace the benefits of sustainable energy sources (Gaventa et al, 2015). Once the European Union's energy market is consolidated the increased competition among different stakeholders would create enhanced demand for innovation products leading reduced costs, including the environmental ones and maximized benefits (Szulecki et al, 2016). General Electric (2016) pointed up that in order to raise the efficiency of the EU energy sector a robust and resilient market is needed. It is inferred that $€ 2$ trillion of investment is required to build and upgrade the European energy infrastructure in the following decade. Achieving this level of investment requires the public and private sectors working together to find the best technologies and solutions, creating a framework for long-term investment.

The improvement of energy sustainability should not be regarded as an isolated process. It should consider all the economic areas as only in this way it will be possible to build efficient economic structures capable of facing the present time economic challenges. The EU stresses this imperative condition as since the implementation of Lisbon Strategy, the innovative activity and innovation has been linked to entrepreneurship, social cohesion and liberalization (Gajewski, 2017). Moreover, it should not be diminished the role of concentrating financial and research resources in technology and capital equipment innovation which are the main drivers of both manufacturing growth and aggregate economic growth (United Nations Industrial Development Organization, 2015). Ćetković and Buzogány (2016) as well as Reinaud et al (2016) marked that capital investment in energy generation capacities and storage across the European Union must rely on well-defined strategies and policies to avoid the situation of technological replication. The divergent positions of EU members in this regard could lead to financial restraints and energy market distortions.

Concluding the section it could be mentioned that the literature reviewed in this paper defines the overall problem and underlines some of the most important motivations to innovate in the energy sector (for instance the increase of competitiveness in the growing global change), the benefits which could be obtained (including lower environmental cost of energy and higher output) and the impediments (irregularities 
in policies across the EU countries and lack of unique energy market). However, further research is needed to more clearly assess and quantify the interconnection between innovation and sustainability of European energy sector by describing the dominant innovation paradigms and policy considerations.

\section{Methodology}

The methodology of the present research is based on qualitative and quantitative analyses of data regarding innovation and energy sustainability of the European Union. In this way, it is possible to have a comprehensive insight upon the research matter and therefore reach relevant conclusions.

Qualitative information regards the innovation and sustainable development initiatives and policies, strategies and methods through which the European Union aspires to reach its objectives in innovation and energy areas. The qualitative analysis is performed through the prism of investigating the general framework of innovation and its paradigms. Then, the present research intends to clarify the conceptual interface between innovation and sustainable energy identifying the main tangential aspects of relevance for the researched matter. Afterwards, it is proposed to be covered the most demanding challenges of the European Union energy sector which serve as significant push factors for investing in innovation and pay increased attention to sustainable economic development. Subsequently, it is possible to examine the main directions of the EU's innovation and sustainable energy initiatives marking their importance in the general framing.

Quantitative data refers to innovation inputs and indicators of sustainable energy development outputs. Thus, inputs are generally presented through R\&D spending while outputs through selected energy sustainability indicators including the share of renewable energy in the gross final energy consumption; level of greenhouse gas emissions; energy efficiency; waste recycling capacities (Wilson, 2012). Quantitative analysis is performed by assessing the European Union's innovation performance in relation with the GDP expenditure on research and development. In such a way, it is possible to analyze the relation between innovation and the sustainability of the EU energy sector by considering two dimensions a) some isolate effects of R\&D expenditures on crucial clean energy technologies and b) the general impact of R\&D expenditures upon the economic competitiveness of European Union countries. The first dimension is evaluated through assessing the correlation between the EU countries' GDPs shares allocated towards R\&D and the shares of renewable energy in the total consumption balance. Also, it is rated the correlation between GDPs shares allocated to R\&D and the quantity of greenhouse gas emissions of the European Union countries. The second dimension is exemplified through establishing the correlation between GDPs shares allocated to R\&D and the level of energy intensity of the EU economies (GDP per oil $\mathrm{kg}$ ). Likewise, it is determined the correlation between, also, the EU countries' GDP shares allocated to R\&D and the material recycling (kg per capita).

In this way, it is possible to clarify whether it is connection between R\&D expenditure and innovation at the EU level, and if so how innovation shown through R\&D affects specific sustainable energy directions and the general sustainability of the EU's economies. 


\section{Innovation and the main related paradigms}

Innovation is an important part of human civilization due to which the humans came to dominate the world. The issue of innovation is one of the most debated among scientific, business and politic environments representing a determinant priority for the decision making factors. Researchers during the study of innovation have determined several paradigms. In the present paragraph it is shortly presented some of the main ones to have a fundamental background on which the further research is built. Mahdjoubi (2009) grouped the paradigms of innovation based on the principles of evolutionary economics starting from the primitive to advance. In the first stage the innovation was mostly determined and provoked by trial and error invention represented by individual characters and lack of systematization. The next stage is called systematic innovation which was in vogue during the second half of $19^{\text {th }}$ and the beginning of $20^{\text {th }}$ centuries. Yet, this is relative as different regions of the world industrialized unevenly. Systematic innovation is driven by system approaches to invention which is created and promoted mainly in universities and research centers. The R\&D paradigm of innovation is closely linked to "cold war", when the two leading superpowers, the communist USSR and capitalist USA, got involved in so called "arms' race" (Plous, 1993). Despite the world was on the verge of extinction, the global society benefited from many inventions including the internet. A different paradigm of innovation is represented by technology and market development integration the main feature of which is represented by the invention on the base of which a whole new market is created, for example the market of modern cellphones. Last point is defined by the user created content innovation when the consumer directly participates in the creation of new products, the possibility widely exploited through modern IT technologies (Mahdjoubi, 2009).

Chesbrough (2003) propose two innovation paradigms and namely those of open and close innovation. Open innovation is a relatively new concept which describes the possibility of firms and individuals to market freely their inventions and ideas to others, while close innovation promotes inventing only for the own use of the entity or individual. The concept of open innovation is connected to user and cumulative innovation, know-how trading, mass, crowdsourced and distributed innovation.

The social driven innovation (Khan, 2017) includes the inventing processes conducted to solve certain societal needs, it does not necessarily presuppose profit. The scopes of innovation in this case are attained through group or individual activism, virtual volunteering, microcredit facilities, or distance learning possibilities. Another recent innovation paradigm relates to innovation network ecosystems. Its main feature is the presence of a centric ecosystem on the base of which it is performed the cross organizational innovation. The degree of openness in this case is much higher as compared to open innovation due to almost no influence of organizational structures upon trading innovation (Curley and Salmelin, 2013).

All the previous mentioned paradigms do not presuppose strict division in time and space and can overlap or co-exist. The distinction is made only with the purpose of making evident the features characteristic either for an epoch or company, or saying in other words the dominant tendencies and attitudes regarding innovation processes. By specifying the previous paradigms it is intended to underline the various aspects driving or stimulating innovation which should be taken into account in order to have efficient and effective approaches to developing respective policies. 


\section{Clarifying the conceptual interface between innovation and sustainable energy}

The Brundtland Commission has defined sustainable development as the "development that meets the needs of the present without compromising the ability of future generations to meet their own needs (IISD, 2017). The key word from this citation is "needs". The greatest need of the human civilization in the $21^{\text {st }}$ century is the need for energy. Namely, energy is the input powering every kind of economic activity people are involved in. Presently, energy is determined by fossil fuels which have multiple advantages including: relatively accessibility; safety; stability; abundancy and ease in exploiting.

Although many would argue regarding these benefits, the majority agrees that fossil fuels are not sustainable as the resources are limited, environmental impact highly negative and even hazardous and they are unevenly distributed across the globe. Indifferently of our attitude towards fossil fuels, it is a fact that modern civilization needs oil, gas and coal until there is no counterbalancing alternative. The situation is alarming, the problem of energy sustainability is worsening in the conditions of expanding world's population and, respectively, growing human hunger for energy supplies. Therefore, it is an imperative condition to underline that the sustainable energy is the solution, having low impact upon the environment and human health and being characterized by manageable collateral effects (Boie et al, 2014).

The modern energy challenge of human civilization could only be tackled through innovating and changing approaches to innovation to maximize the benefits offered by modern technologies. Sustainability of energy supplies could be assured either by identifying alternative sources or through developing technologies of capturing greenhouse gases. Moreover, rationalization of use and optimization of polluting processes should also be taken into account. Thus, it can be noticed that it is a direct link between innovation and energy sustainability (Nidumolu et al, 2009). By innovating, human civilization is able to identify new solutions to the current and future challenges including in the energy sector.

The paradigms which have been covered in the previous paragraph express the various methodologies people have developed in solving widely different issues. There is a wide range of factors which should be taken into account when developing innovation policies as to identify the most influential levers to be used. Furthermore, as innovation in the energy sector to be lucrative, it should have efficient paths of implementation on the markets as to replace the present technologies. Therefore, the markets are able to change the current economic system which puts enormous pressure upon the planet. The advanced markets of energy supplies will quickly replace the obsolete ones, thus stimulating the sustainable development of the human civilization.

\section{Most demanding challenges of European Union's energy sector}

Presently, politicians, experts and scientific researchers agree that the energy sector of the European Union and of the world as a whole should innovate to be capable of effectively riposting to the current energy challenge. Despite the multitude of energy threats, some of them are most dangerous menacing the EU and world's security and prosperity. The extent to which these threats menace the global security is 
the most relevant indicator determining stakeholders to undertake right actions and search for best. The most debated and evident challenge of the European and world's energy sector regards the current economic dependency on the fossil fuels and especially oil-gas resources. The global oil-gas economic vulnerability is constantly rising. This problem not only includes the negative environmental effects but also the fluctuating price connected to foreign policy issues of most politically unstable regions of the world which are reach in these resources. Besides this threat, the dependency of some European Union states and EU neighboring countries on just one source perils the socio-politic and economic stability in the region. The next energy threat which needs innovation to be solved regards the huge investment costs in developing and maintaining the infrastructure functional to assure high quality services to consumers, constant generation power and not affected environment. Moreover, at the level of the European Union there are also problems referring to industrial discrepancies among the member states. Yet, the EU is succeeding to reduce them by its cohesion programmes (Crudu and Ignatov, 2016a).The last issue menacing the EU energy security has rather a global impact. The present scale greenhouse gas emissions, the rise in the energy demand of constantly growing global population and growing global temperature can cause irreversible processes which can inevitably bring the globe to an edge (Gallagher et al, 2006).

\section{The European initiatives on innovation and sustainable energy development}

The most important programme of the European Union establishing the priorities for sustainable development of its energy sector is the EU 2020 strategy. The main goal is to promote a more resource efficient, greener, and more energy competitive economy. It provides strategic guidelines to develop new efficient processes and technologies to reduce the fossil fuels dependency and increase the diversification of energy supplies for European consumers. A determinant point of the strategy is put on EU innovation networks and smart ICT grids which are invited to develop new energy sources taking into account the present issues of environmental degradation and bio-diversity loss (European Commission, 2010).

A special attention is offered towards keeping the present European leadership in green economic technologies, despite the fact that the global competition from China, USA and Japan is rising fast. European Union intends to maintain and improve the positions in the green economy through the use of high end technologies and re-adjusting its energy infrastructure to cover the present energy needs with minimum impact upon the climate and environment. The EU stakes on 60 billion EUR less imports of gas and oil by 2020 which besides additional savings provide higher energy security. It is necessary to remind that the quantitative goal of the EU regarding its sustainable energy development resumes to at least $20 \%$ of all energy consumption to be covered by renewable sources by the 2020. Furthermore, it supposes to reduce the greenhouse gas emissions by $20 \%$ as compared to 1990 , or even $30 \%$ given the right conditions. Also, Europe 2020 intends to achieve a $20 \%$ increase in the energy efficiency in the same period (European Commission, 2011).

The Europe 2020 strategy aims to reach the goals of sustainable energy development by realising the following flagship initiatives in the area of energy including Resource efficient Europe and An industrial policy for the globalisation era. It is necessary to underline that the strategy was adopted in 2010 as an initiative of the 
European Commission to boost economic development of the community. Besides the sustainable development, Europe 2020 emphasized the role of innovation in modern society and set as a target for the member countries to invest at least $3 \%$ of their GDP into R\&D, stimulating especially the participation of private sector in this process (European Commission, 2010). The Europe 2020 strategy was preceded by Lisbon strategy (Lisbon Agenda) which determined the main European Union development objectives during the 2000-2010. According to this document, sustainable energy development was prioritized. Energy security was established as a directive of the community, special attention being given to the greenhouse gas emissions control and the development of renewable energy (Gajewski, 2017).

When speaking about EU initiatives on innovation it is a must mentioning the Horizon 2020 programme which was established in 2014 with the general purpose to foster innovation related activities in the member countries. Nearly 80 billion EUR funding has been allocated by the European Union till 2020 to reach the goals of this programme, not considering the money provided by the private sector. The Horizon 2020 is the financial instrument of implementing the flagship initiative of Europe 2020 strategy Innovation Union. The Horizon 2020 programme includes 10 sections covering a wide range of areas including innovation in ecologic related issues, industrial processes and SMEs (Crudu and Ignatov, 2016b). The overall benefits expected, as a result of implementation of the Horizon 2020 initiative, are the following: higher economic development; lower unemployment; more efficient scientific activities; higher competitiveness of the industrial sector; cleaner and more protected environment. The Horizon 2020 programme should assure the European Union a breakthrough in technology and innovation fields stimulating the consolidation of a unique EU market for knowledge and research (Crudu and Ignatov, 2016b).

Besides the above mentioned initiatives of the European Union on innovation and sustainable development of its energy sector, there are several other projects either undertaken at the EU institutional level or at the national one. For instance, the Energy 2020 strategy is established since y. 2010 and is intended to foster the consolidation of internal energy market, make more efficient energy management, and stimulate the infrastructure development (European Commission, 2011). Moreover, the Commission has consolidated efforts in assuring energy security for the member states by elaborating the European Energy Security Strategy (European Commission, 2015). The document includes major actions undertaken to consolidate energy solidarity among members, moderate energy demand, increase energy production, invest in further development of energy technologies and improve the national coordination. There are also other initiatives of the EU to assure either maximization of energy efficiency and minimisation of environmental impact or improve the energy technologies, including through the actions CEPHEUS (ultra-low energy housing), SAVE (energy saving), ALTENER (new and renewable energy sources), STEER (transport) (European Commission, 2017). The EU is also participating at various international clean energy initiatives. Thus, through the Fusion for Energy, the European Union participates at ITER (International Thermonuclear Experimental Reactor) programme (ITER, 2016). It is also necessary to underline that besides all R\&D efforts, the European Union intends to create a unique energy market which will comprise all EU member states. This fact is going to provide additional economic opportunities because of lower prices for energy supplies, more stable provision and increased security and independence from external factors conditions which are imperative for sustainability. 


\section{The European Union innovation performance and its relation with the GDP expenditure on research and development}

Measuring innovation performance is a challenge intriguing many academics, business representatives, policy decision makers and investors. Fortunately, the European Commission developed the European Innovation Scoreboard intended to evaluate the innovation competitiveness of the EU member countries through analysing relevant areas. The indicator allows comparing the evolution of innovation across EU and some of neighbouring countries underlining both the weaknesses and strengths reported by the states. The index is complex comprising 8 base directions on which the overall performance is determined including: human resources; research systems; availability of financing; firms' investments; entrepreneurship networks; intellectual assets; main innovators and respectively the economic effects resulting from the innovation activity.

Based on the information provided in the figure 1, it can be observed that the innovation score reported by the European Union, on average, within the period of 2008 to 2015 has constantly increased except for the last year. At the same time it can be noticed that the value of GDP expenditures on R\&D increased also in dynamics from $1.84 \%$ to $2.03 \%$. It is important to underline that there is a strong correlation index of 0.97 between the innovation score reported by the European Union on average and the volume of GDP spent on R\&D.

This fact allows inferring that the increase of the GDP expenditures on $R \& D$ will stimulate the progress in the innovation field with at least the same rate as there is almost perfect correlation between these two variables. Thus, the EU goal to reach at least $3 \%$ of GDP to be allocated towards research and development related processes and activities will certainly improve the innovation performance of the community. Therefore, if the European Union intends to keep up with the increasing global competition, it is a must to develop policies motivating both the private and public sector to allocate more financial resources to innovation to strengthen its economic potential.

Fig. 1: The Innovation Index of the European Union and EU share of GDP expenditure on R\&D

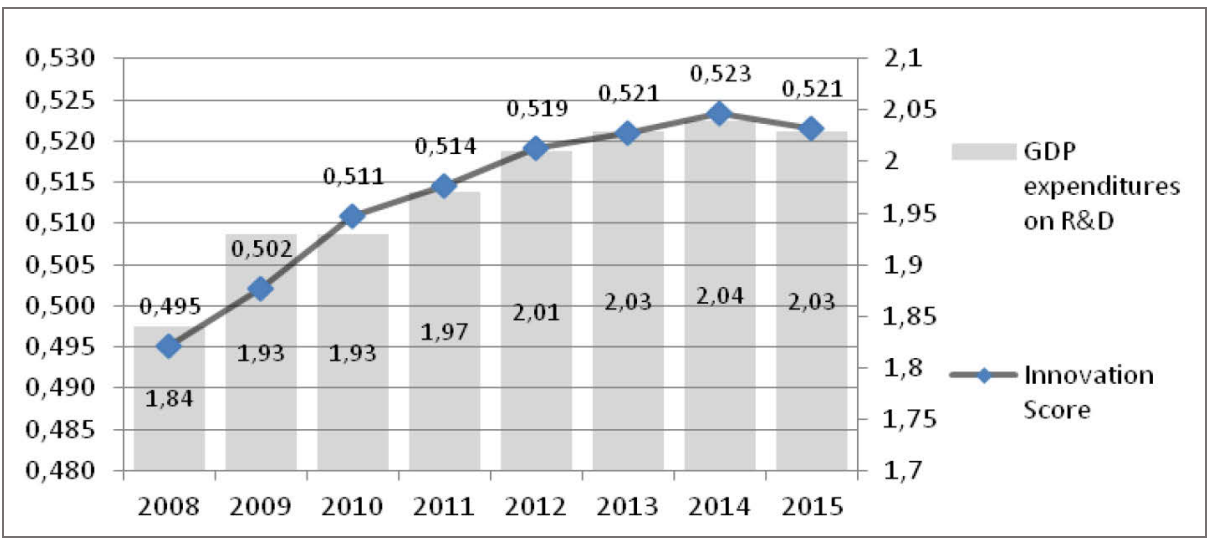

Source: Drafted by the authors based on data provided by the European Commission (EUROSTAT) (2008-2015) 


\section{Analysing the relation between innovation and the sustainability of EU energy sector}

Energy innovation is the totality of all processes which lead towards the improvement of relating technologies which enhance the resource efficiency, quality of services and assure sustainability by lowering economic, political and environmental risks in the energy sector. In this paragraph it will be analysed the interconnection between innovation and several indicators related to sustainable development. The relation is assessed by covering two most relevant dimensions such as: first, some isolate effects of R\&D expenditures on crucial energy technologies; second, the general impact upon the economic competitiveness assessed through the general stability of the energy prices, energy connected infrastructure and future development prospective. In this way it is assured a comprehensive understating of the impact of innovation upon the economic sustainability of the European Union.

\subsection{Some isolate effects of R\&D expenditures on crucial clean energy technologies: A. renewable energy generation capacities; B. energy related green-house gases emissions}

A. It has been performed the correlation analysis between the GDP share allocated towards R\&D and the share of renewable energy in the total EU consumption balance (figure 2). Consequently, it has been received an almost perfect correlation of 0.97 at the level of the European Union. By far the vast majority of countries recorded strong positive correlation ranging between Italy, 0.99, and UK, 0.72 . Only eight countries out of 28 registered lower correlations than 0.72 while just 4 of them reported negative correlation (figure 2). It is necessary to mention that the datasets comprise the period of 2004-2015.

Fig. 2: Summary of the correlations between GDPs share allocated towards R\&D and the share of renewable energy in the total consumption balance

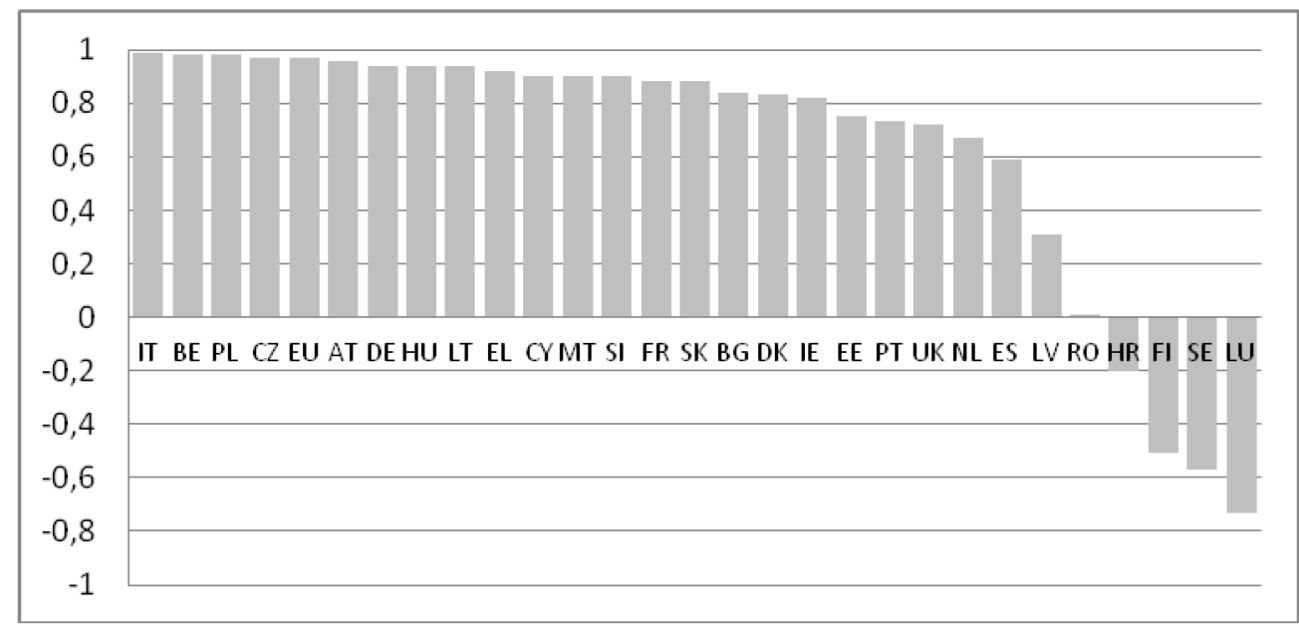

Source: Designed by the authors based on own calculations. Data sources: European Commission (EUROSTAT) (2004-2015) 
B. An important indicator of sustainable energy is a lower quantity of greenhouse gases emissions poured into atmosphere as a result of at least the same level human activity. Therefore, it is an imperative task to analyse the relation between the R\&D spending and the volume of pollutants released into the air, in this case the stronger the negative correlation the more favourable is effect of the R\&D expenditure on lowering the level of greenhouse gases emissions.

The results summarising the correlations are provided in the figure 3 . It could be underlined that the general correlation at the communitarian level is -0.97 . This almost perfect negative correlation means that the higher the EU GDP spending on R\&D activities the lower is the level of greenhouse gas emissions released by the EU into the atmosphere. In such a way, the European Union's intention to allocate at least $3 \%$ of GDP to R\&D will have a positive impact upon the energy sustainability. As it can be also observed in the figure 3 the vast majority of European Union countries registered a strong negative correlation between R\&D spending and the level of greenhouse gases emissions, starting with Hungary, -0.98 , and finishing with Slovenia, -0.59 . Only six countries out of 28 registered positive correlation, a discrepancy from the other countries which can be explained by the national policies' peculiarities and differing economic structures. On overall, it can be remarked the positive effects of European Union's energy and innovation policies on the reduction of greenhouse gases emissions.

Fig. 3: Correlation between GDPs share allocated to R\&D and the quantity of greenhouse gas emissions of the European Union countries

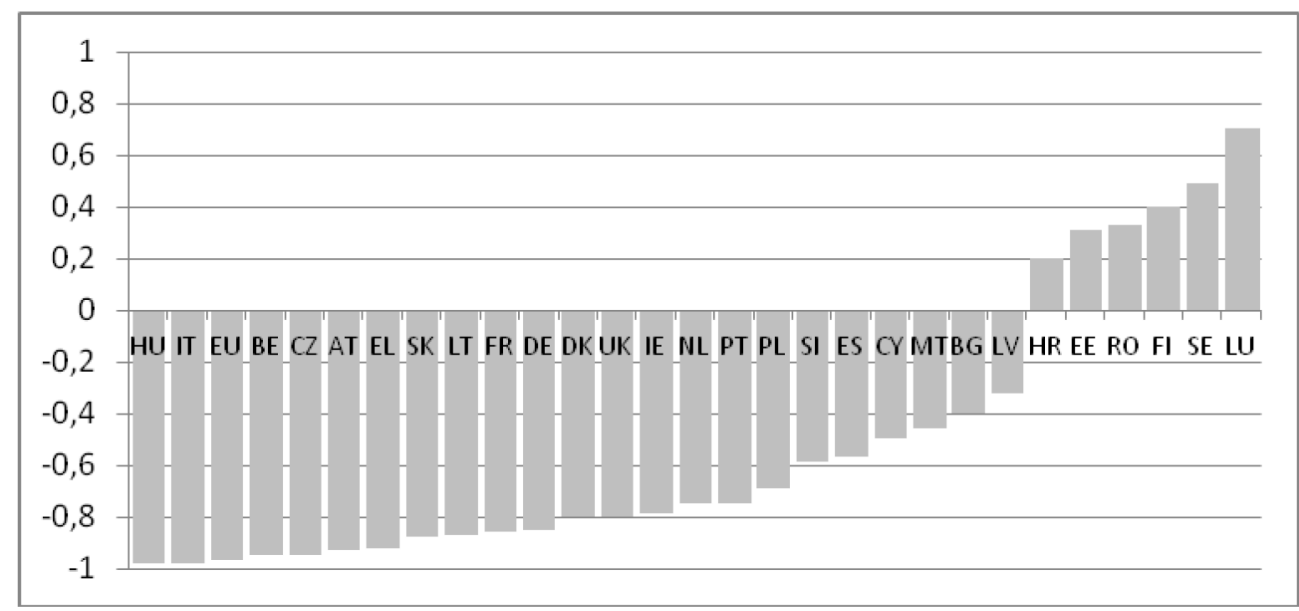

Source: Designed by the authors based on own calculations. Data sources: European Commission (EUROSTAT) (2004-2015)

9.2 The general impact of R\&D expenditures upon the economic competitiveness of European Union countries: A. Energy intensity of economy (GDP per oil $\mathbf{k g}$ ); B. Material recycling (kg per capita)

A. Energy intensity is one of the most relevant indicators of economic efficiency. It is also relevant when speaking about sustainable development as succeeding in producing more welfare from less or the same quantity of energy consumed means 
progress, the pressure upon the environment being decreased. According to the figure 4, it can be underlined that there is strong correlation between R\&D spending and the level of economic energy intensity. Thus, it can be remarked that the overall EU correlation index is 0.92 which proves the necessity to allocate more funding for innovation as to improve the energy intensity of the community. Moreover, at the national level the vast majority of countries register either strong or medium strong correlations starting with Italy, 0.96, and finishing with Netherlands, 0.54 . Only seven countries out of 28 report either weak positive correlation or negative one.

\section{Fig. 4: Correlation between GDPs share allocated to R\&D and the level of energy intensity of EU economies (GDP per oil kg)}

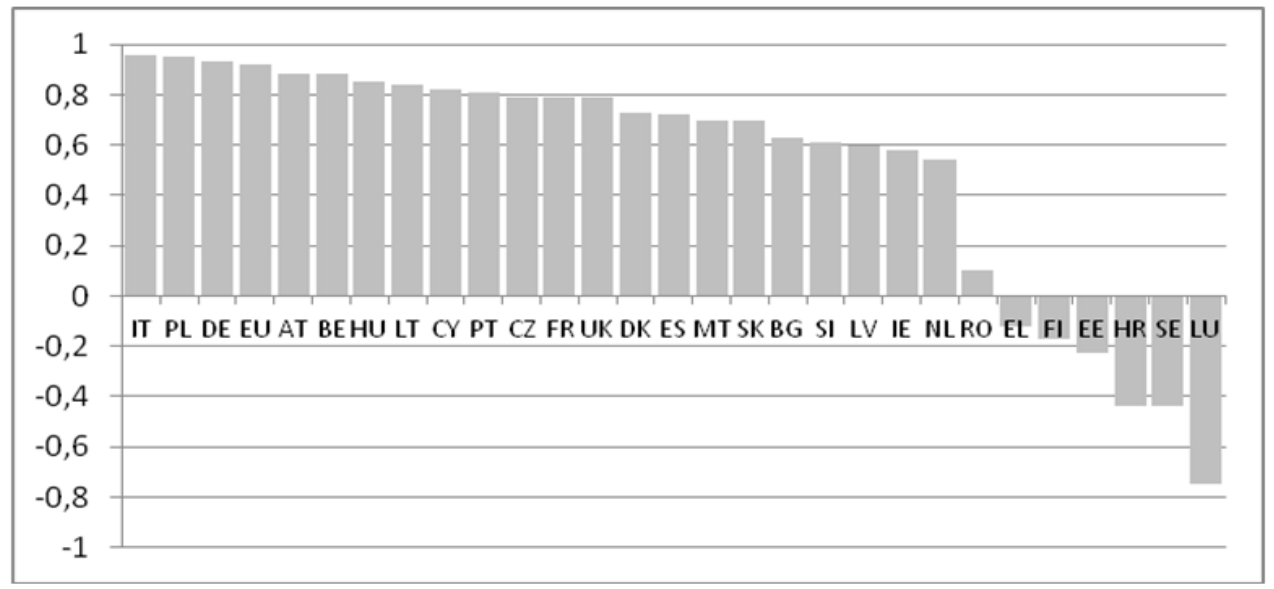

Source: Designed by the authors based on own calculations. Data sources: European Commission (EUROSTAT) (2004-2015)

In this way, it can be stated that the policies promoted at the level of the European Union as well as at the national one had favourable impact upon overall energy intensity of the community's member countries.

B. Material recycling is one of the most important indicators of sustainable economic development and has direct connection with the minimisation of energy waste. The idea is based on the fact that making a product from recycled materials always consumes much less energy as when making it from raw materials as many production stages are omitted. According to EIA (2017) it will require 95\% less energy to make new aluminium cans from recycled ones than producing them from aluminium ores. Besides this, by recycling it is reduced the environmental pressure. For instance, by recycling a ton of used paper it can be saved 17 trees. Also, for making paper from recycled materials $50 \%$ less water is involved in the production process. Therefore, this indicator is fundamental and is must to be analysed to have a deeper comprehension of how efficient is the effect of EU innovation policies upon the sustainability of its energy sector. 
Fig. 5: Correlation between GDPs share allocated to R\&D and material recycling kg per capita

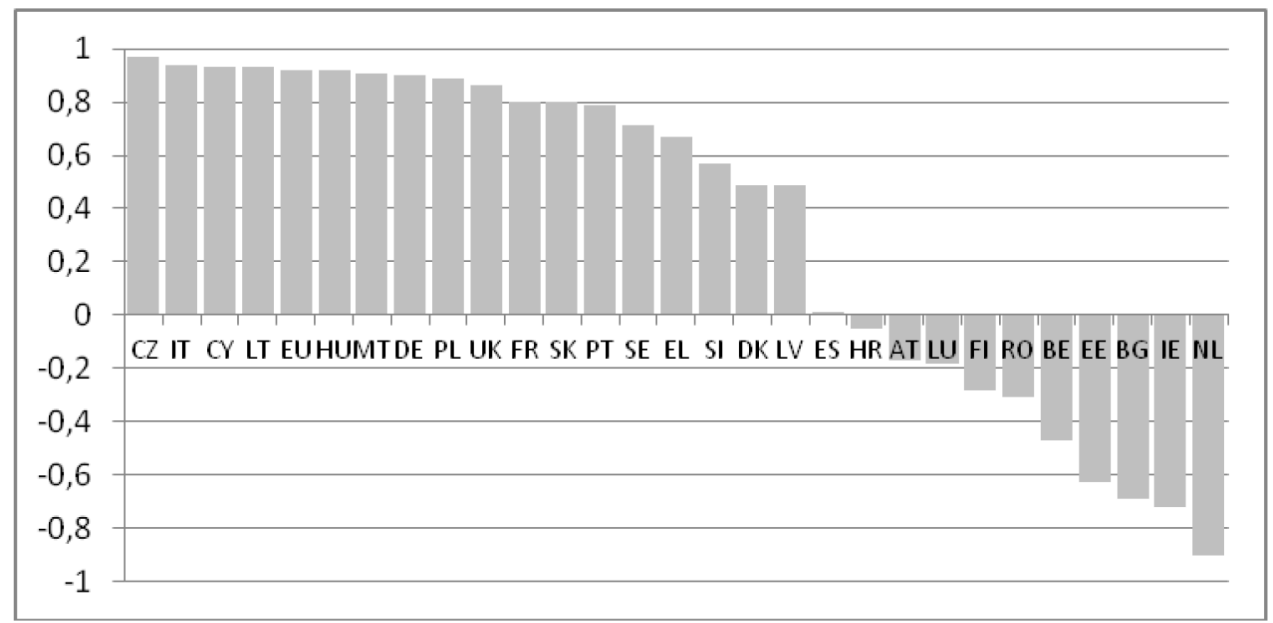

Source: Designed by the authors based on own calculations. Data sources: European Commission (EUROSTAT) (2004-2015)

By analysing the figure 5, it can be underlined that the allocation of additional R\&D funding will have a positive effect upon the overall European Union performance in recycling materials. So, the general correlation at the European level between these indicators is 0.92 (strong). At the level of EU member countries the vast majority of states (17 out of 28) record strong or medium strong correlation between R\&D expenditure and the material recycling per capita.

In such a way, the EU policies in the innovation area are beneficial for the enhancement of its economic potential taking into consideration the needs of sustainability. The European Union by innovating set up higher sustainability standards regarding the promotion of energy efficiency and economic competitiveness minimising the negative effects of socio-economic activity upon the environment and human health. Therefore, it is an imperative obligation to direct further efforts in maximising energy intensity and recycling capacities in order to reduce economic waste.

\section{Conclusion}

The investments the community has made into R\&D during the researched period on overall stimulated innovation performance of the European Union. Thus, taking into consideration the results of the present research it can be concluded that innovation initiatives and policies promoted by the European Union in the period of 2004-2015 have shown a highly favourable impact upon the sustainable development of its energy sector. These initiatives made the EU the leading global power in terms of sustainable development and environmental protection setting high standards for the world as a whole.

The evolution of sustainability of European energy sector was assessed through correlating R\&D investments with I) the share of renewable energy in gross final energy consumption; II) level of greenhouse gas emissions; III) energy efficiency; 
IV) waste recycling capacities (Annex 1). As the summary of correlations shows (Annex 1), the enlargement of investments into research and development at the community level as well as at the level of EU countries stimulated the sustainability and development of European energy sector. In this regard, the intention of the European Union to reach at least 3\% of GDP allocated towards R\&D expenditure by 2020 (Europe 2020 strategy) is expected to stimulate even greater the energy sustainability of the EU.

The success of the European Union in assuring sustainable development of its energy sector is reached through comprehensive approach towards the energy issue. In this way, there have been developed initiatives to minimise material and energy waste, improve energy efficiency, and enhance renewable energy capacities. The EU progress in this matter is an indicator of improving socio-economic competitiveness neither damaging nor worsening the quality of the environment. The European Union is a pace ahead of all other global powers in developing a new generation of economy based on sustainability.

Finally, it is important to mention that a limiting factor of the present research was the difficulty in qualitatively assessing the heterogeneity of European Union member countries in terms of innovation and energy sustainability. It occurs as a result of countries' geographical position and the complexity of their economic structure. Thus, some of the EU countries are more dedicated towards developing sustainable energy technologies in the wind area (Netherlands or Denmark) while other could exploit the geo-thermic potential (Italy) or bio-energetic one (Romania). Also, it is necessary to point out that the correlation as a quantitative method of analysis could not be quite precise and relevant in individual cases, nevertheless, in most of time it shows the general trend and direction the fact which could be used in developing policies and strategies.

There are plenty of theoretical and practical applications for the results of this research such as designing future energy \& innovation strategies and activity frameworks. Still, it is important to develop further studies taking into consideration the multitude of other aspects of this policy area and in more detail discuss particular features. Therefore, this paper encourages future research on the issues related to innovation and energy sector of the European Union as this fact will provide additional insight and provoke discussions leading to better understanding of the matter.

Generally, one fact is sure, in the future the attention the EU is paying to innovation related processes and sustainability of its energy sector will increase. This fact is fuelled both by the external factors including the global competition raise and internal ones such as the increase in the complexity of related market demand. 


\section{Annex 1: Summary of correlations*}

\begin{tabular}{|l|r|r|r|r|}
\hline Correlation & \multicolumn{1}{l|}{ I } & \multicolumn{1}{l|}{ II } & \multicolumn{1}{l|}{ II } & \multicolumn{1}{l|}{ IV } \\
\hline Austria & 0,96 & $-0,93$ & 0,88 & $-0,17$ \\
\hline Belgium & 0,98 & $-0,95$ & 0,88 & $-0,47$ \\
\hline Bulgaria & 0,84 & $-0,40$ & 0,63 & $-0,69$ \\
\hline Croatia & $-0,20$ & 0,20 & $-0,44$ & $-0,05$ \\
\hline Cyprus & 0,90 & $-0,50$ & 0,82 & 0,93 \\
\hline Czech Republic & 0,97 & $-0,95$ & 0,79 & 0,97 \\
\hline Denmark & 0,83 & $-0,80$ & 0,73 & 0,49 \\
\hline Estonia & 0,75 & 0,31 & $-0,23$ & $-0,63$ \\
\hline EU & 0,97 & $-0,97$ & 0,92 & 0,92 \\
\hline Finland & $-0,51$ & 0,40 & $-0,17$ & $-0,28$ \\
\hline France & 0,88 & $-0,86$ & 0,79 & 0,80 \\
\hline Germany & 0,94 & $-0,85$ & 0,93 & 0,90 \\
\hline Greece & 0,92 & $-0,92$ & $-0,12$ & 0,67 \\
\hline Hungary & 0,94 & $-0,98$ & 0,85 & 0,92 \\
\hline Ireland & 0,82 & $-0,79$ & 0,58 & $-0,72$ \\
\hline Italy & 0,99 & $-0,98$ & 0,96 & 0,94 \\
\hline Latvia & 0,31 & $-0,32$ & 0,60 & 0,49 \\
\hline Lithuania & 0,94 & $-0,87$ & 0,84 & 0,93 \\
\hline Luxembourg & $-0,73$ & 0,70 & $-0,75$ & $-0,18$ \\
\hline Malta & 0,90 & $-0,46$ & 0,70 & 0,91 \\
\hline Netherlands & 0,67 & $-0,75$ & 0,54 & $-0,90$ \\
\hline Poland & 0,98 & $-0,69$ & 0,95 & 0,89 \\
\hline Portugal & 0,73 & $-0,75$ & 0,81 & 0,79 \\
\hline Romania & 0,01 & 0,33 & 0,10 & $-0,31$ \\
\hline Slovakia & 0,88 & $-0,88$ & 0,70 & 0,80 \\
\hline Slovenia & 0,90 & $-0,59$ & 0,61 & 0,57 \\
\hline Spain & 0,59 & $-0,57$ & 0,72 & 0,01 \\
\hline Sweden & $-0,57$ & 0,49 & $-0,44$ & 0,71 \\
\hline UK & 0,72 & $-0,80$ & 0,79 & 0,86 \\
\hline & & & & \\
\hline
\end{tabular}

Source: Designed by the authors based on own calculations

${ }^{*}$ Grey colour indicates correlations which express a favourable impact of innovation related expenditures on energy sustainability indicators 


\section{References}

*International Institute for Sustainable Development (IISD) (2017) Sustainable Development, Available online at: http://www.iisd.org/topic/sustainable-development

*International Thermonuclear Experimental Reactor (ITER) (2016) Progress in ITER Construction, Manufacturing and R\&D, IAEA Fusion Energy Conference, Kyoto, Japan

*European Commission (2010) Europe 2020 A strategy for smart, sustainable and inclusive growth, Brussels, Belgium

*European Commission (2011) Energy 2020 A strategy for competitive, sustainable and secure energy, Publications Office of the European Union, Luxembourg

*European Commission (2015) State of the Energy Union 2015, Commission Staff Working Document on the European Energy Security Strategy SWD(2015), Brussels, Belgium

*European Commission (2017) Intelligent Energy Europe, Projects database. Available online at: http://ec.europa.eu/energy/intelligent/projects/

*European Commission (EUROSTAT) (2004-2015), Database, available online at: http://ec.europa.eu/eurostat/data/database

*European Commission (EUROSTAT) (2008-2015), Database, available online at: http://ec.europa.eu/eurostat/data/database

*United Nations Industrial Development Organization (2015) Industrial Development Report 2016. The Role of Technology and Innovation in Inclusive and Sustainable Industrial Development, Vienna

*Boie I., Fernandes C., Frías P., Klobasa M. (2014), Efficient strategies for the integration of renewable energy into future energy infrastructures in Europe An analysis based on transnational modeling and case studies for nine European regions, Energy Policy, 64 (1), 170-185

Ćetković S., Buzogány A. (2016) Varieties of capitalism and clean energy transitions in the European Union: When renewable energy hits different economic logics, Climate Policy, 16 (5), 642-657

Chesbrough H. W. (2003) The Era of Open Innovation, MIT Sloan Management Review, 44 (3), 34-42

Costa-Campi M.T., Duch-Brown N., García-Quevedo J. (2013) R\&D Drivers and Obstacles to Innovation In the Energy Industry, IEB Working Papers 2013/23, Barcelona, Spain

Costantini V., Crespi F. (2009) Public Policies For A Sustainable Energy Sector: Regulation, Diversity And Fostering Of Innovation, Dipartimento di Economia "S. Cognetti de Martiis" Working papers No. 15/2009, Torino (Italy)

Crudu R., Ignatov A. (2016a) The Role Of EU Financing In The Industrial Development of EU New Member States, 25 De Ani de Reformă Economică în Republica Moldova: Prin Inovare şi Competitivitate spre Progres Economic Conference, Chişinău, Republic of Moldova

Crudu R., Ignatov A. (2016b) The role of innovation policies in economic sustainable development of the EU, Economica, 98 (4), 71-87

Curley M., Salmelin B. (2013) Open Innovation 2.O: A New Paradigm- White paper, OI2 Conference Paper, Dublin, Ireland

Enel, The European House "Ambrosetti" (2015) Building the European Energy Union, Primaprint - Viterbo, Rome 
Gajewski M. (2017) Policies Supporting Innovation In The European Union In The Context Of The Lisbon Strategy And The Europe 2020 Strategy, Comparative Economic Research, 20 (2), 109-127

Gallagher K. S, Holdren J. P., Sagar, A. D. (2006) Energy-technology innovation, Annual Reviews, 31 (1), 193-237

Gaventa J., Mabey N., Dixson-Declève S., Spence-Jackson H., Acke D. (2015) EU Energy Union Assessment 2015 Towards A Resilient Energy Union With A Forward-Looking Climate Policy, Briefing Paper November 2015, University of Cambridge, European Climate foundation

General Electric (2016) The Investment Plan for Europe- A GE Perspective, GEJW 2016/02, Brussels, Belgium

Hamdouch A., Depret M-H. (2012) Sustainable Development Policies and the Geographical Landscape of the Green Economy. Actors Scales and Strategies, Finisterra, 47 (94), 49-80

Khan R. (2017) The contribution of socially driven businesses and innovations to social sustainability, Lappeenrannan teknillinen yliopisto, Yliopistopaino

Mahdjoubi D. (2009) Paradigms of Innovation, Stavanger Centre for Innovation Research Workshop, Austin, Texas

Nidumolu R., Prahalad C.K., Rangaswami M.R. (2009) Why sustainability is now a key driver of innovation. Harvard Business Review, 87 (9), 57-64

Plous S. (1993) The Nuclear Arms Race: Prisoner's Dilemma or Perceptual Dilemma?, Journal of Peace Research, 30 (2), 163-179

Prandecki K. (2014) The Idea of Sustainability in European Union Energy Policy, Environment and Ecology Research, 2 (1), 14-20

Ragwitz, M.; Schade, W.; Breitschopf, B.; Walz, R.; Helfrich, N.; Rathmann, M.; Resch, G.; Panzer, C.; Faber, T.; Haas, R.; Nathani, C.; Holzhey, M.; Konstantinaviciute, I.; Zagame, P.; Fougeyrollas, A.; Le Hir, B. (2009) EmployRES. The impact of renewable energy policy on economic growth and employment in the European Union. Final report, Brussels, Belgium

Reinaud J., Clinckx N., Ronzeau K., Faraggi P. (2016) Scaling Up Innovation in the Energy Union to Meet New Climate, Competitiveness and Societal Goals, i24c, European Climate Foundation

Szulecki K., Fischer S., Gullberg A. T., Sartor O. (2016) Shaping the 'Energy Union': between national positions and governance innovation in EU energy and climate policy, Climate Policy, 16 (5), 548-567

Williams R. H. (2001) Addressing challenges to sustainable development with innovative energy technologies in a competitive electric industry, Energy for Sustainable Development, 5 (2), 48-73

Wilson C. (2012) Input, Output \& Outcome Metrics for Assessing Energy Technology Innovation. Historical Case Studies of Energy Technology Innovation. In: Grubler A., Aguayo F., Gallagher K.S., Hekkert M., Jiang K., Mytelka L., Neij L., Nemet G., Wilson C. (eds). The Global Energy Assessment. Cambridge University Press: Cambridge, UK, Chapter 24 